Original Article

\title{
Surgical Outcome of Anterior Cervical Decompression and Fusion in Patients with Cervical Spondylotic Myelopathy and Radiculopathy in Terms of Improvement of Pain
}

\author{
Hamayun Tahir ${ }^{1}$, Afzal Raza ${ }^{2}$, Mumtaz $\mathrm{Ali}^{3}$, Naseer Hassan1, Muhammad Ayaz ${ }^{4}$, Hina Arooj ${ }^{5}$, \\ Zulfiqar Ali Shah ${ }^{6}$ \\ ${ }^{1}$ Department of Neurosurgery, Qazi Hussain Ahmed Medical Complex/Nowshera Medical College \\ Nowshera, Medical Teaching Institute (MTI), KPK, Pakistan \\ ${ }^{2}$ Department of Orthopedics Max Health hospital, Islamabad, Pakistan \\ ${ }^{3}$ Department of Neurosurgery, Prime Teaching Hospital, Lady Reading Hospital Peshawar, Pakistan \\ ${ }^{4}$ Department of Neurosurgery, Saidu Teaching Hospital, Saidu Medical College Swat, Pakistan \\ ${ }^{5}$ Department of Orthotics \& Prosthetics, Advance Care Medical Facility Abu Dhabi, UAE \\ ${ }^{6}$ Medical officer Department of Neurosurgery DHQ hospital, Charssada, Pakistan
}

\begin{abstract}
Objective: Cervical spondylosis is a common degenerative condition leading to compression of nerve roots or spinal cord, causing radiculopathy or myelopathy. Anterior cervical decompression and fusion (ACDF) techniques are commonly recognized procedures in treating axial cervical spine pain and upper extremity radicular discomfort. The study analyzed the surgical outcome of anterior cervical decompression and fusion (ACDF) in cervical spondylotic myelopathy (CSM) and radiculopathy patients in terms of pain improvement.
\end{abstract}

Material and Methods: This descriptive case series analysis was performed at the Neuro Surgery department, Lady Reading Hospital Peshawar. A total of 146 patients between age 18 - 65 years meeting the inclusion criteria underwent anterior decompression \&post-procedure improvement in pain of neck and arm/shoulder was determined using patient reported outcome (PRO) measure, namely visual analog scale (VAS) of 0-10 and a final outcome that is an improvement of pain, i.e., Mild to no pain (VAS score $\leq 3$ ) was considered after 12 months.

Results: The mean age was 52 years \pm 8.273 . As regards gender distribution, $78 \%$ of patients were male, while $22 \%$ were female. The mean baseline VAS score was $6.5 \pm 2.37$, mean postoperative VAS score was $3.5 \pm$ 1.161 with a mean point improvement in pain of 3.0 points ( $p$-value $<0.05$ ). $80 \%$ of patients had shown improvement in reducing pain, while $20 \%$ did not have shown any improvement.

Conclusion: This study revealed that independent of symptoms duration and presentation, patients reported dramatic improvements in neck and arm pain after ACDF.

Keywords: Surgical Outcome, Anterior Cervical Decompression and Fusion (ACDF), Cervical Spondylotic Myelopathy (CSM), Radiculopathy. 
Corresponding Author: Hamayun Tahir

Department of Neurosurgery, Qazi Hussain Ahmed Medical Complex/Nowshera Medical College Nowshera, Medical Teaching Institute (MTI), KPK, Pakistan

Email: hamayun_tahir@ymail.com

Date of Submission: 20-01-2021

Date of Revision: 24-02-2021

Date of Online Publishing: 31-03-2021

Date of Print: 31-03-2021

DOI: $0.36552 /$ pjns.v25i1.506

\section{INTRODUCTION}

Cervical spondylotic myelopathy (CSM) is a common debilitating cervical spine cord disorderinduced via narrowing of the cervical spinal canal due to age-induced degenerative changes and genetic modifications leading to substantial neurological impairment. ${ }^{1}$ It is commonly seen in patients above the age of 50 years. ${ }^{2}$ Three clinical syndromes can be broadly defined as complications caused by cervical spondylosis: axial neckline pain, cervical radiculopathy, cervical myelopathy, and some patients, usually experiencing a mixture of these syndromes. ${ }^{3}$ Patients typically have neck pain symptoms that radiate to the upper limb, particularly the arms, headache, and myelopathic weakness. In more extreme cases, depending on the cord level involved, fine motor coordination may be lost and even contribute to full upper and lower limb paralysis. ${ }^{4}$

When myelopathy occurs, surgical procedures are the recommended treatment. Conservative approaches that might include analgesia, cervical traction, immobilization, skull traction, antiinflammatory drugs, physical therapy, and epidural analgesia are used in patients who are moderately impaired by Cervical spondylotic myelopathy (CSM). ${ }^{4,5}$ Surgical care is intended for those patients who have progressive neurological problems or intractable pain. Nerve impingement due to cervical spondylosis can be addressed with either a posterior or anterior route. Similarly, it is possible to decompress the spinal cord through any route. ${ }^{5}$ The two primary decompression modalities in which an anterior approach is followed are anterior cervical corpectomy and fusion (ACCF) and anterior cervical discectomy and fusion (ACDF). High clinical effectiveness and increasing fusion rates had been reported after anterior discectomy and fusion, and both approaches have proved to be secure and effective. ${ }^{2,6}$

The literature review doesn't show explicitly that one approach is scientifically superior to another but evaluates a variety of surgical techniques that exist, including both posterior or anterior approach either with or without fusion. Decision making thus focuses on patient variables and concomitant complications correlated to the strategy. The aims of surgical treatment should be decompression of the spinal cord or nerve roots, preventing deformity by preserving or supplementing the cervical spinal column's essential integrity, and alleviating neck and arms pain. ${ }^{5,7}$ Despite other parameters, it is important to consider reducing axial neck pain and arm pain.

Because further research on pain
improvement after anterior cervical
decompression and fusion appears to be
required, studies that focus on surgical results of such procedures would be useful. This study's aim is in line with the same intent, which evaluates pain improvement after employing anterior cervical decompression \pm fusion in patients having cervical spondylotic myelopathy and radiculopathy in our local population. One of the critical reasons for this study is that only one such analysis by Arif et al. has been identified so far in our region. ${ }^{4}$ This study's results would be projected on different health care institutions to improve treatment measures, and these findings can deliver neurosurgeons of knowledge about the probability and gradation which their patients 
would encounter symptom changes following an ACDF.

\section{MATERIAL AND METHODS}

\section{Study Design and Setting}

A descriptive case series analysis was performed at the Neuro Surgery department, Lady Reading Hospital Peshawar, from January 2019 to January 2020. A total of 146 patients, through nonprobability consecutive sampling, taking $75.3 \%$ proportion of improvement in pain of neck and arm, $^{6} 7 \%$ margin of error and $95 \%$ confidence level under WHO formula for sample size, meeting inclusion criterion were enrolled in the study.

\section{Inclusion Criteria}

Patients of either gender with age between 18 65 years, diagnosed as per operational definition having unbearable pain (VAS - visual analog score four and above). Patients with one-level disease, i.e., either at C3 - C4 through C7 - T1, including one or a mixture of signs and symptoms such as arm or shoulder pain, motor weakness, altered sensations, and abnormal reflexes, and myelopathic symptoms. Patients not responding to conservative measures for more than 6 weeks.

\section{Exclusion Criteria}

Patients with prior failed cervical fusion, prior cervical trauma causing substantial bony or discoligamentous injuries to cervical spine $\&$ radiographically confirmed facet joint pathology. Patients with comorbidities such as severe diabetes mellitus and obesity, autoimmune disorders such as rheumatoid arthritis, malignancy of and/or metastatic to the cervical spine, osteoporosis, local or systemic infections, and allergic to implant materials were excluded from the study.

\section{Data Collection}

The analysis was carried out after the hospital's ethical \& research committee's appraisal (Institutional board review PGMI Lady Reading Hospital Peshawar (Ref no: 1070Dy/reg/PGMI). Patients were informed of the research and treatment's intent and advantage, and written informed consent was received. All patients have been exposed to a detailed history of the duration of symptoms and Neurological examination. The cervical spondylotic myelopathy diagnosis was based on the operational definition.

A single neuro spine surgeon performed the anterior decompression at a single academic institution through a team of neuro spine surgeons with extensive experience of more than one year in their specialties. Post-procedure patients were followed regularly as per departmental protocol (2-weeks, 1-month, 3months, 6-months, and one year). All the information, including name, age, gender, address, baseline VAS, and post-op VAS, was recorded in a proforma before and after the procedure and during follow-up uptill one year and an outcome that is an improvement of pain (VAS score three or less) was considered after 12 months. To restrict confounders and bias in study outcomes, strict exclusion criteria were followed.

\section{Data Analysis}

Using SPSS Version 20, the collected data was analyzed. Mean \& Standard deviation was calculated for continuous variables such as age, duration of symptoms, height, weight, BMI, baseline VAS, post-op VAS. Categorical variables such as gender, obesity \& pain improvement were stated as Percentages and frequencies. Effect modifiers such as gender, age, duration of symptoms, and obesity (BMI > 27.5) were dealt with through stratification to see these effects on the outcome. Post-stratification, the chi square 
test was applied, holding a p-value of $\leq 0.05$ as significant \& results were expressed as tables.

\section{RESULTS}

\section{Gender Distribution}

In our study, 114 (78\%) patients were male, while 32 (22\%) were female.

\section{Age Range}

The age-wise distribution of 146 patients was observed, as 20 (14\%) patients were within 31 and 40 years, 51 (35\%) patients were in between 41 and 50 years, 75 (51\%) patients were in 51 and 65 years of age. The mean age was $52 \pm 8.273$ years.

\section{Clinical Presentation}

The duration of symptoms was evaluated as 61 (42\%) patients had a $1-3$ months course, while 85 (58\%) patients had $4-6$ months with a mean duration of 3 months \pm 2.149 . The status of obesity was evaluated as 92 (63\%) patients were non-obese (BMI < 27.5) and 54 (37\%) were obese (BMI > 27.5) with a mean BMI of $26 \pm 3.451$. Mean, and the standard deviation was evaluated for numerical variables as mean height was 5.5 feet \pm 1.76 , mean weight was $77 \mathrm{Kgs} \pm 9.23$.

\section{Outcome Analysis}

The mean baseline VAS score was $6.5 \pm 2.37$, mean postoperative VAS score was $3.5 \pm 1.161$ with a mean point improvement in pain of 3.0 points ( $p$-value 0.001 , which is less than 0.05 ). The status of improvement in pain among 146 patients was evaluated as 117 (80\%) patients showed improvement in reducing pain, while 29 (20\%) patients did not improve.

Stratification of improvement in pain for, gender, age, duration of symptoms, and obesity is given in Tables 1-3.
Table 1: Stratification of Improvement in Pain with respect to Gender Distribution ( $n=146)$.

\begin{tabular}{lrrr} 
Variable & Male & Female & Total \\
Improvement in pain: & & & \\
Improved & 91 & 26 & 117 \\
Not improved & 23 & 6 & 29 \\
Total & 114 & 32 & 146 \\
\hline
\end{tabular}

Table 2: Stratification of Improvement in Pain with respect to Age Distribution $(n=146)$.

\begin{tabular}{lcccr} 
Variable & $\begin{array}{c}\mathbf{3 1 - \mathbf { 4 0 }} \\
\text { Years Age }\end{array}$ & $\begin{array}{c}\mathbf{4 1 - 5 0} \\
\text { Years Age }\end{array}$ & $\begin{array}{c}\mathbf{5 1 - 6 5} \\
\text { Years } \\
\text { Age }\end{array}$ & Total \\
Improvement in pain: & & & & \\
Improved & 16 & 41 & 60 & 117 \\
Not improved & 4 & 10 & 15 & 29 \\
Total & 20 & 51 & 75 & 146 \\
\hline
\end{tabular}

The chi square test was applied, where $\mathrm{p}$ value was 0.8582 for gender-wise \& 0.9984 for age-wise distribution.

Table 3: Stratification of Improvement in Pain with respect to Duration of Symptoms \& Obesity ( $\mathrm{n}=$ 146).

\begin{tabular}{|lccr|} 
Variable & $\mathbf{1} \mathbf{- 3}$ Months & $\mathbf{4} \mathbf{- 6}$ Months & Total \\
Improvement in pain: & & & \\
Improved & 49 & 68 & 117 \\
Not improved & 12 & 17 & 29 \\
Total & 61 & 85 & 146 \\
Variable & Non-Obese & Obese & \\
Improvement in pain: & & \\
improved & 74 & 43 & 117 \\
Not improved & 18 & 11 & 29 \\
Total & 92 & 54 & 146 \\
\hline
\end{tabular}

The chi square test was applied, where $\mathrm{p}$ value was 0.9609 .

\section{DISCUSSION}

Cervical spondylosis is a degenerative condition leading to compression of nerve roots and spinal cord, causing radiculopathy or myelopathy. ${ }^{6}$ 
Anterior cervical decompression and fusion (ACDF) techniques are commonly recognized procedures in treating axial cervical spine pain and upper extremity radicular discomfort. ${ }^{8,9}$ Previous literature testified success rates of up to $94 \%$ and about $96 \%$ of patients suggesting that they remained pleased with the treatment or very satisfied with it. ${ }^{9-12}$ Previous findings have shown that postoperative improvements in axial neckline pain and radicular arm pain could beof utmost significance in patients satisfaction. ${ }^{9}$ The patientreported outcome scales (PRO), as the visual analogue scale for pain, are frequently used to determine treatment outcomes after spinal surgery concerning treatment response and functional impairment. ${ }^{13}$ Prior literature analyzed surgical features and PROs (VAS) after anterior cervical surgery. ${ }^{9,13,14}$ Limited trials, however, have measured and stratified the gradation of improvement in pain (neck and arms discomfort) that somehow patient may experience after an ACDF after the first postoperative year.

Our study results revealed that most patients ( $n=117$ ) could expect improvement in their axial neck pain and arm pain afterwards, the first postoperative year following anterior cervical decompression \pm fusion. VAS arm \& neck pain improvedfrom preoperative baseline in 80 percent of patients. Comparison of means between two independent variables, i.e. Mean baseline VAS \& Mean postoperative VAS, showed a statistically significant difference between two groups with a p-value of 0.001 which is less than 0.05 and a mean point improvement in pain of 3.0 points. Improvements in arm pain are expected to occur following discectomy and intervertebral disc space height restoration leading to decompression of impinged nerve roots, while neck pain seems likely to improve because of bone fusion of the involved segment.

The current findings further indicate that patients with pain as the primary symptom undergo the most significant improvement (3.0 Points decline) in their respective condition irrespective of age, gender, obesity, duration of symptoms ( $p$-value $>0.05$ ). It is expected to occur because a higher pain score as a primary symptom has a tremendous recovery prospect. In another study performed by Phillips FM et al, $^{6}$ similar findings were reported wherein mean VAS pain values improved substantially over preoperative levels overall postoperative periods, with $75.3 \%$ of patients who underwent anterior cervical discectomy \pm fusion had testified a clinically significant reduction in axial neck pain and worst arms discomfort. ${ }^{6}$

Zigler et al. $^{15}$ reported that most of the improvements in patient complaints measured by the visual analogue scale were found in the first six weeks after surgery; however, the authors have not stated the degree of improvement in the assessed patient-reported outcome measure. ${ }^{15}$ Carreon et al. ${ }^{16}$ observed a 2.4 points (33.3\%) decline in axial neck pain and a 2.2 points (35.5\%) decrease for arm pain. Still, despite the vast pool of patients, the researchers had not provided the number of disease levels or that their research's fusion methods were through an anterior or posterior approach, limiting applicability to anterior cervical fusions only ${ }^{16}$.

Our work wasn't without restrictions. Firstly, all operations were carried out by a neurosurgeon at one tertiary care institute. This could restrict the generalization of the findings to the whole population undertaking anterior cervical decompression \pm fusion. Secondly, there was a limited overall number of patients included within our study, so strictly speaking, this analysis could be under powered $\&$, therefore, may provide a restricted valuation of the amount of progress encountered by ACDF patients.

\section{CONCLUSION}

The findings of our research indicate that patients can observe noteworthy improvements in their neck and arm pain, independent of their age, gender, and obesity \& duration of symptoms 
after an ACDF and could expect a 3.0 mean point reduction (80\% improvement) over the first postoperative year.

\section{REFERENCES}

1. Wen Z-Q, Du J-Y, Ling Z-H, Xu H-D, Lin X-J. Anterior cervical discectomy and fusion versus anterior cervical corpectomy and fusion in the treatment of multilevel cervical spondylotic myelopathy: systematic review and a metaanalysis. Ther Clin Risk Manag. 2015; 11: 161-70.

2. Lau D, Chou D, Mummaneni PV. Two-level corpectomy versus three-level discectomy for cervical spondylotic myelopathy: a comparison of perioperative, radiographic, and clinical outcomes. J Neurosurg Spine SPI. 2015; 23 (3): 280-9.

3. Butler JS, Oner FC, Poynton AR, O'Byrne JM. Degenerative cervical spondylosis: natural history, pathogenesis, and current management strategies. Adv Orthop. 2012; 2012: 916987.

4. Arif $M$, Hassan $W$, Inam $M$, Wali K SM. Functional outcome of anterior cervical decompression and fusion in cervical myelopathy and degenerative disc diseasee. Khyber J Med Sci. 2011; 3 (2): 56-61.

5. Galbraith JG, Butler JS, Dolan AM, O'Byrne JM. Operative outcomes for cervical myelopathy and radiculopathy. Adv Orthop. 2012; 2012: 919153.

6. Phillips FM, Lee JYB, Geisler FH, Cappuccino A, Chaput CD, DeVine JG, et al. A prospective, randomized, controlled clinical investigation comparing PCM cervical disc arthroplasty with anterior cervical discectomy and fusion. 2-year results from the US FDA IDE clinical trial. Spine (Phila Pa 1976). 2013; 38 (15): E907-18.

7. Yalamanchili PK, Vives MJ, Chaudhary SB. Cervical spondylotic myelopathy: factors in choosing the surgical approach. Adv Orthop. 2012; 2012: 783762.

8. Chang H, Baek D-H, Choi B-W. The Relationship between Increased Intervertebral Disc Height and Development of Postoperative Axial Neck Pain after Anterior Cervical Fusion. J Korean Neurosurg Soc. 2014; 55 (6): 343-7.
9. Hessler C, Boysen K, Regelsberger J, Vettorazzi E, Winkler D, Westphal M. Patient satisfaction after anterior cervical discectomy and fusion is primarily driven by relieving pain. Clin J Pain. 2012; 28 (5): 398-403.

10. Burkhardt J-K, Mannion AF, Marbacher S, Dolp PA, Fekete TF, Jeszenszky $D$, et al. A comparative effectiveness study of patient-rated and radiographic outcome after 2 types of decompression with fusion for spondylotic myelopathy: anterior cervical discectomy versus corpectomy. Neurosurg Focus, 2013; 35 (1): E4.

11. Erickson $M$, Fites BS, Thieken MT, McGee AW. Outpatient anterior cervical discectomy and fusion. Am J Orthop (Belle Mead NJ). 2007 Aug; 36 (8): 429-32.

12. Peolsson A, Vavruch L, Oberg B. Predictive factors for arm pain, neck pain, neck specific disability and health after anterior cervical decompression and fusion. Acta Neurochir (Wien). 2006; 148 (2): 16773; Discussion 173.

13. Auffinger BM, Lall RR, Dahdaleh NS, Wong AP, Lam SK, Koski T, et al. Measuring surgical outcomes in cervical spondylotic myelopathy patients undergoing anterior cervical discectomy and fusion: assessment of minimum clinically important difference. PLoS One, 2013; 8 (6): e67408.

14. Pool JJM, Ostelo RWJG, Hoving JL, Bouter LM, de Vet HCW. Minimal clinically important change of the Neck Disability Index and the Numerical Rating Scale for patients with neck pain. Spine (Phila Pa 1976). 2007; 32 (26): 3047-51.

15. Zigler JE, Rogers RW, Ohnmeiss DD. Comparison of 1-Level Versus 2-Level Anterior Cervical Discectomy and Fusion: Clinical and Radiographic Follow-Up at 60 Months. Spine (Phila Pa 1976). 2016; 41 (6): 463-9.

16. Carreon LY, Glassman SD, Campbell MJ, Anderson PA. Neck Disability Index, short form-36 physical component summary, and pain scales for neck and arm pain: the minimum clinically important difference and substantial clinical benefit after cervical spine fusion. Spine J. 2010; 10 (6): 469-74. 


\section{Additional Information}

Disclosures: Authors report no conflict of interest.

Ethical Review Board Approval: The study was conformed to the ethical review board requirements.

Human Subjects: Consent was obtained by all patients/participants in this study.

Conflicts of Interest:

In compliance with the ICMJE uniform disclosure form, all authors declare the following:

Financial Relationships: All authors have declared that they have no financial relationships at present or within the previous three years with any organizations that might have an interest in the submitted work.

Other Relationships: All authors have declared that there are no other relationships or activities that could appear to have influenced the submitted work.

\section{AUTHORS CONTRIBUTIONS}

\begin{tabular}{|l|l|l|}
\hline Sr.\# & Author's Full Name & Intellectual Contribution to Paper in Terms of: \\
\hline 1. & Hamayun & Study design and methodology, manuscript writing and correspondence. \\
\hline 2. & Afzal Raza & Paper writing, referencing, and data calculations. \\
\hline 3. & Mumtaz Ali & Data collection and calculations. \\
\hline 4. & Naseer Hassan & Analysis of data and interpretation of results etc. \\
\hline 5. & Mohammad Ayaz & Literature review and manuscript writing. \\
\hline 6. & Hina Arooj & Analysis of data and quality insurer. \\
\hline 7. & Zulfiqar Ali Shah & Analysis of data and quality insurer. \\
\hline
\end{tabular}

